\title{
DOM QUIXOTE, O ACOMPANHAMENTO TERAPÊUTICO E UM TESTEMUNHO DA LOUCURA COMO PRÁTICA QUIXOTESCA DA LIBERDADE
}

\author{
Aline Fagundes Silva ${ }^{1}$ \\ Carine Gatto ${ }^{2}$ \\ Fernanda Denise Satler ${ }^{3}$ \\ José Alberto Orsi ${ }^{4}$
}

\begin{abstract}
"A liberdade, Sancho, é um dos mais preciosos dons que os homens receberam dos céus. Com ela não podem igualar-se os tesouros que a terra encerra nem que o mar cobre; pela liberdade, assim como pela honra, se pode e deve aventurar a vida (...)" (Miguel de Cervantes).
\end{abstract}

\section{RESUMO}

O presente trabalho tem como base a leitura do livro Dom Quixote de La Mancha, escrito por Miguel de Cervantes, proposta na disciplina de "Fundamentos Históricos e Filosóficos em Saúde Mental, Atenção e Reabilitação Psicossocial”, oferecida pelos Programas de Pós-Graduação em Saúde Mental e Atenção Psicossocial e em Saúde Coletiva, vinculados à Universidade Federal de Santa Catarina. Após um breve relato e contextualização da obra entrelaçamos as jornadas de Dom Quixote e Sancho Pança na Mancha do início do Século XVII com o encontro entre o usuário de serviços de saúde mental e o acompanhante terapêutico, neste caminhar da Reforma Psiquiátrica do nosso tempo. Por fim, trazemos o relato de vivências de um Quijote dos dias atuais, usuário e ativista da saúde mental, relacionando-o à obra estudada.

Palavras-chave: Dom Quixote; Acompanhamento terapêutico; Luta antimanicomial.

\section{A OBRA}

Dom Quixote de La Mancha é obra do escritor Miguel Saavedra de Cervantes, publicada em duas partes, a primeira em 1605 e a segunda em 1615. Apesar desse

\footnotetext{
${ }^{1}$ Psicóloga Clínica e Acompanhante Terapêutica.

${ }^{2}$ Assistente Social e Mestranda em Saúde Mental e Atenção Psicossocial - UFSC.

${ }^{3}$ Psicóloga e Mestrando em Saúde Coletiva - UFSC.

${ }^{4}$ Diretor Da Associação Brasileira de Familiares e Amigos de Pessoas com Esquizofrenia - ABRE e doutorando em Saúde Mental - Unifesp.
} 
intervalo entre as publicações, a história apresenta uma continuidade impressionante. Curiosamente, a segunda parte foi escrita por Cervantes depois que uma pessoa não identificada, usando o nome de Alonso Fernandez Avellaneda, publicou a suposta segunda parte da obra, valendo-se do enorme sucesso da primeira parte.

À época, novelas de cavalaria eram muito populares, e retratavam principalmente o período que antecedeu a unificação da Espanha, que se instituiu como Estado moderno centralizadoem 1469. Estas novelas eram produzidas em um contexto de reconhecimento da reconquista espanhola depois de séculos de domínio muçulmano na Península Ibérica. A história da Espanha conta que nobres feudais trataram de vencer pela "capa e espada" a avançada organização econômica, política e militar dos muçulmanos (MULINARI, 2019).

O livro narra a história do fidalgo Alonso Quijano, filho da nobreza espanhola que, apaixonado por livros de cavalaria, e já em avançada idade, decide abandonar a casa e a fazenda eassume a identidade de Dom Quixote, cavaleiro andante. Influenciado pela literatura, nosso cavaleiro providencia uma armadura e um cavalo, Rocinante, elege um amor imaginário inspirado em uma paixão da juventude e consegue um fiel escudeiro, Sancho Pança, que o acompanha na esperança de ser recompensado. Põe-se então a percorrer, com seu cavaloe seu escudeiro,a região circunvizinha, precisamente "La Mancha".

Em suas andanças, o cavaleiro mistura fantasia e realidade e encontra tanto personagens que identificam o fidalgo como louco, tanto os que embarcam na sua loucura e compartilham suas histórias imaginárias. Dom Quixote usa a imaginação para reinventar o mundo, trazendo experiências de aventura, beleza, dignidade e nobreza onde não mais se enxergava quemarasmo, feiúra, pobreza e vulgaridade. Cria este mundo imaginário como válvula de escape de uma vida banal e monótona.

Mas a reinvenção da vida pode custar caro. Em inúmeras passagens, o fidalgo sofre escárnio, deboche e humilhação eé ferido em lutas com inimigos imaginários. Mesmo assim se sente animado e feliz com suas realizações. A certa altura, frente a sua imagem cansada e devastada, Sancho Pança nomeia-oO Cavaleiro da Triste Figura. Vale aqui o parêntesis de que este título concedido pelo escudeiro a Quixote nos lembrou, como profissionais de saúde mental, as pessoas que, incompreendidas em suas diferenças e perspectivas de mundo, tornam-se pessoas emsofrimento, vítimas de preconceitos, objetos de discursos da psiquiatria e da prática de profissionais de saúde. 
Seu fiel escudeiro, Sancho Pança, tenta, em diferentes momentos, trazer o fidalgo à razão, mas seus esforços são em vão. Várias pessoas que encontra pelo caminho dizem conhecer sua história, pois já seria então famoso, mas zombam de seus ideais e suas ilusões.

Entrementes, a sobrinha do cavaleiro, preocupada com sua saúde, junta-se ao padre eao barbeiro, que o diagnosticam como louco. Conseguem então trazê-lo de volta para casa e destroem sua "nefasta" biblioteca, o que Dom Quixote identifica como obra de um feiticeiro inimigo.

Estes três personagens parecem representar instituições: família (sobrinha), igreja (padre) e ciência (barbeiro). Ao ludibriar Dom Quixote e trazê-lo de volta para casa, aos cuidados da família, tanto o padre quanto o barbeiro, movidos pelo sentimento de adequação à ordem, assumem o encargo de "curá-lo" da loucura promovida pelos livros de cavalaria.

Dom Quixote volta, entretanto, a suas aventuras. Seu amigo Sansão Carrasco, mais uma vez monta um plano para salvá-lo de suas ilusões, usando a loucura a seu favor, em um duelo pela honra de sua amada. Desta vez o cavaleiro sai derrotado e humilhado e retorna para sua casa e apesar de nutrir novos planos e novas histórias acaba doente e deprimido por não poder mais viver plenamente suas fantasias e aventuras. Em seu leito de morte recupera sua consciência, pede perdão à família e aos amigos, especialmente a Sancho Pança. Renega, assim, seus ideais e rende-se, afinal, à Razão.

Dom Quixote abandonou sua identidade social e colocou para si a incumbência de recuperar a grandeza de uma Espanha que se modernizava. Virtudes cavalheirescas como o amor cortês, a disposição ao sacrifício e a coragem heróica, contudo, já não mais tinham grande espaço nos tempos que se impunham. Os cenários das aventuras retratam o conflito entre o ideário e os valores de uma época em relação àquela que se avizinhava. Mesclando drama e humor, loucura e candura, a obra de Cervantes delata a ambiguidade frente aos dogmas do mundo, do império, da ciência e da igreja, mostrando que as verdades são múltiplas e parciais, e que o que era concebido como heróico em um tempo passa a ser entendido como desvario em outro.

Dom Quixote é apenasaté certo ponto o nobre idealizado nos romances de cavalaria. Cervantes debocha dos estereótipos e sua obra, entre muitas deste tipo de romance, é única, não só pela riqueza literária, mas pela presença constante do inusitado. 
Quixote não é o que se espera de umtípico cavaleiro herói. É um homem velho, com uma armadura tosca, um cavalo pangaré e acompanhado de um escudeiro nada convencional.

Dom Quixote de La Manchaprovoca no leitor riso e compaixão, excitação e reflexão, orgulho e indignação. O idealismo, o senso de justiça, a loucura, o ridículo e a comicidade estão presentes todo o tempo na saga de Quixote.Entretanto, todas essas ambigüidadesfazem com que ele nos pareça muitas vezes mais simpático, mais humano e mais sincero que seus contemporâneos racionalistas.

\section{SANCHO PANÇA E O ACOMPANHANTE TERAPÊUTICO}

Dom Quixote e Sancho Pança se complementam. Um traz a visão do idealismo e o outro do realismo. Sancho é a voz da razão, mas em muitos momentos contagia -se pela loucura do amigo, levado por seu desejo porprometidasrecompensas, e acaba por tornar-setambém um sonhador. Mas quando é, enfim, recompensado, tornando-se governador, percebe que dinheiro e poder não são sinônimos de felicidade, mas geram desconfianças e medo.

Dom Quixote pode ser visto como um louco ou como alguém disposto a tudo pelos seus sonhos. Ele nos lembra a importância de não nos acomodarmos, de vivermos e lutarmos pela liberdade. Cervantes retrata o amor, desta forma, como uma "loucura permitida".

Intercambiamos as vivencias de Dom Quixote e sua luta pela liberdade de viver seus sonhos com o trajeto percorrido pelos usuários dos serviços de saúde mental no contexto da Luta Antimanicomial. Neste sentido, Sancho Pança nos remete, de algumas maneiras, à atuação do profissional de saúde na função de Acompanhante Terapêutico (AT) que, tal como o escudeiro, tem entre suas atribuições pleitear a mediação entre a realidade e a fantasia.

Como observado na literatura, já existem trabalhos que relacionam os personagens desta obra com a proposta de AT, como o conceituado livro "Ética e técnica no acompanhamento terapêutico: andanças com Dom Quixote e Sancho Pança" de Kleber Barretto (1998), que apresenta experiências do cotidiano do acompanhante terapêutico articulado a referências teóricas de Winnicott.

O Acompanhamento Terapêutico é reconhecido como dispositivo clínico-político e estratégico para o Movimento da Luta Antimanicomial.Quando nos referimos ao AT como um dispositivo, parte-se do entendimento de que este é parte de uma rede que se 
estabelece entre os diferentes elementos de um conjunto heterogêneo, que "engloba discursos, instituições, organizações arquitetônicas, decisões regulamentares, leis, medidas administrativas, enunciados científicos, proposições filosóficas, morais, filantrópicas" (PALOMBINI, 2006). Na dimensão clínica o AT possibilita o gerenciamento e manejo de demandas direcionadas aos sujeitos e suas respostas. Já o sentido político da função do acompanhante enseja o deslocamento da clínica para a interlocução e enfrentamento ao terceiro, com a intenção de provocar desejo ou uma resposta da ordem da inteligência social (MÜLLER-GRANZOTTO, MÜLLER-GRANZOTTO, 2012).

Ele é acompanhante porque é companheiro, companheiro político daquele a quem acompanha pelo bem (ou pelo mal) da vida social, pelo bem (ou pelo mal) do outro social a quem serve (ou contra quem conspira); o que faz dele terapeuta: aquele que serve ao semelhante (MÜLLER-GRANZOTTO, MÜLLER-GRANZOTTO, p. 253, 2012).

No livro, Sancho Pança, nomeado escudeiro, é reconhecido como companheiro de Dom Quixote, que em seus devaneios cria e se envolve em diferentes aventuras, como a luta contra os moinhos de vento, as confusões na estalagem, a luta contra os odres de vinho e a penitência realizada em nome da sua amada Dulcinéia Del Toboso.Assim também,encontra em seu percursooutras histórias, como do jovem Grisóstomo, que se suicidou por não ter o amor correspondido pela sua amada, as narrativas de Cardênio, Lucinda, Don Fernando e Doroteia marcadas por histórias de paixão, amizade, traição, lealdade, redenção e desventuras.

No acompanhamento terapêutico é proposto que o usuário de serviços de saúde mental não apenas ocupe outros lugares da cidade/comunidade, mas também provoque o desejo no outro social e, desse modo, aceite a manifestação da resposta a esse novo encontro aberto aos acontecimentos imprevisíveis. A loucura de Dom Quixote é acolhida por diversas pessoas que cruzam o seu caminho, que também participam e compartilham da realidade criada pelo personagem.

O AT se constitui como uma estratégia no percurso da luta antimanicomial no Brasil, movimento que conforme se organiza e se articula, pretende transformar as condições, reações e representações da loucura na sociedade (LÜCHMANN, RODRIGUES, 2007). Sancho Pança, assim como muitos que não se limitam a diagnosticar, julgar e medicar, pode ser visto, nesse sentido, como um companheiro de uma personagem que encarna esta luta pela liberação da lógica manicomial. 


\section{UMA TRAJETÓRIA QUIXOTESCA DE NOSSOS TEMPOS: UM TESTEMUNHO VIVO DE LUTA PELA LIBERDADE DE SONHAR (José Alberto Orsi)}

A figura de Dom Quixote,hidalgo, romântico e idealista cavaleiro medieval, apoiado por seu fiel escudeiro Sancho Pança, me traz à lembrança meu percurso na minha virtuosa, apesar de errática, jornada de recovery frente ao transtorno mental.

Fui diagnosticado com transtorno esquizoafetivo aos 26 anos, no auge da minha carreira profissional, enquanto engenheiro civil, quando, ao enfrentar forte período depressivo e de oscilações de humor, além de surto psicótico, tive de tirar uma licença médica do meu trabalho, abandonando, dessa forma, independência financeira, casa própria, noiva e uma perspectiva de vida dentro de uma normalidade que a sociedade nos impõe. Já naquela época, e seguramente convicto com os olhos de hoje, já com larga experiência vivida, não posso deixar de afirmar que a raiz do meu surto psicótico foi quixotesca, ou seja, um excesso de idealismo e inconformismo com a minha árdua realidade de trabalho cotidiano.

Ao me formar, almejava trabalhar e atuar profissionalmente em um contexto que causasse grande impacto de mudanças sociais, como a do urbanismo. Minha idéia era tentar sanar os graves problemas metropolitanos que minha cidade natal, São Paulo, enfrenta, como tráfego caótico, falta de planejamento urbano, desrespeito à legislação de zoneamento, devido a especulação imobiliária, falta de moradia, saneamento, transporte público, entre outros problemas crônicos e insolúveis.

Ora, como um engenheiro civil, quixotesco, resolveria sozinho esses graves problemas sistêmicos e endêmicos, contra forças político-econômicas muito mais poderosas do que eu, um simples sonhador de uma cidade com uma realidade mais humana e solidária? Ao me deparar com a dura realidade do trabalho, com gerenciamento de obras, com operários da construção civil submetidos a trabalho semiescravo, mal remunerado, e sem perspectivas de ascensão profissional, com índice de alcoolismo e rotatividade nos postos de trabalho altíssimos, este ex-engenheiro civil, inconformado, amante da criatividade e das belas artes, incapaz de mudar e alterar a realidade à sua volta sucumbiu e o transtorno mental, de origem depressiva, surgiu e solapou meu equilíbrio emocional.

Um fato corrente e histórico é que muitosdos românticos, idealistas e humanistas da História Humana foram sumariamente e implacavelmente perseguidos, e até assassinados, entre eles, Jesus Cristo, Sócrates, Mahatma Gandhi, Martin Luther King Jr., 
John Kennedy, John Lennon, entre tantos outros. Dom Quixote também fazia parte desse rol de figuras históricas, que lutavam por um ideal, valores ético-morais e de fidalguia, dentro da filosofia e tradição de lealdade a um código de honra do cavaleiro medieval. Não havia alternativa ou outra sina a Dom Quixote, e a mim mesmo, que "enlouquecer" e sucumbir aos Moinhos de Vento e às ciladas da Vida, repleta de pessoas maliciosas, de má fé. O triste fim de Dom Quixote, no entanto, não tira o seu mérito e nos deixa a lição de que vale a pena perseguir os nossos sonhos, custe o que custar, doa a quem doer, com perseverança, mesmo que isso nos cause a morte, ou a loucura.

Felizmente, para mim, depois de tantos surtos e desventuras, estou trilhando um caminho, uma jornada feliz, de processo de recovery, com ascensão acadêmico-profissional, reconstruindo com paixão e idealismo a minha vida dentro do ambiente acadêmico-profissional, tendo completado um mestrado e agora como doutorando e atuando no Terceiro Setor como Diretor de uma ONG voltada para a área de psicoeducação em saúde mental, auxiliando tanto usuários quanto seus familiares em busca de uma "luz no fim do túnel".

\section{CONSIDERAÇÕES FINAIS}

Don Quijote de la Mancha,de Miguel de Saavedra Cervantes, é um dos maiores clássicos da literatura mundial, considerado por muitos a maior obra literária da língua espanhola de todos os tempos. A leitura da obra, no contexto de uma disciplina de Saúde Mental, traz um significado particular dos personagens Dom Quixote e seu escudeiro Sancho Pança para os dias atuais, levando-se em conta o contexto da Reforma Psiquiátrica e da Luta Antimanicomial. Esta leitura permitiu traçar um paralelo com as vivências cotidianas de pessoas com adoecimento mental e o fazer do profissional de saúde.

Durante muito tempo na história da humanidade à loucura, objeto de cuidados mágico-espirituais e posteriormente de tratamento na medicina, cabia quase exclusivamente a clausura em instituições, asilos e hospitais, em nome do bom funcionamento e da ordem social. As Reformas Psiquiátricas, contudo, trouxeram um novo paradigma que nos possibilitou lançar novos olhares para a loucura e para as práticas manicomiais.

O testemunho do Quijote de nossos dias indica uma trajetória com muitos percalços, frente ao sonho de fazer da Engenharia, tecnologia dura e racional, um 
enfrentamento aos graves problemas que uma cidade da dimensão de São Paulo computa. Delírio quixotesco que, desconstruído, foi ressignificado, proporcionado outras possibilidades de ser/estar no mundo, já que o engenheiro de então reconheceu que o ideal de mudança, da forma como pensada, não tinha lugar nestes tempos que correm.

Que outros Quixotes, que produzem realidades de forma diferente da maioria das pessoas, se somam a ele, nos nossos tempos? Quais lugares Ihes são concedidos, nas famílias, nas comunidades, na sociedade e dentro dos serviços de saúde mental?

Arriscamos concluir que, embora a reforma psiquiátrica e a luta dos movimentos antimanicomiais possibilitaram que o protagonismo do usuário esteja no escopo das práticas dos profissionais de saúde mental, a lógica manicomial ainda permeia fortemente a instituição psiquiátrica. Desta forma, o acompanhante terapêutico, como Sancho Pança, se apresenta como estratégia/ferramenta importante de mediação entre o usuário e o outro. Para isso, entretanto, o acompanhante deve estar disposto a desnudar-se de sua lógica racional e permitir o reconhecimento do sonho/ideário por trás do diagnóstico.

Nesse sentido, algumas inquietações continuam necessárias para aqueles que, como Quixote e Sancho, se incumbem deste desafio: qual lugar o usuário de saúde mental ocupa nos espaços da cidade? Que movimento é feito para que sejam respeitados seus direitos humanos e para que sua loucura/sonho sejamacolhidos? Enquanto profissionais da saúde mental, é imprescindível questionar até que ponto não estamos tentando "encaixar" o usuário em um funcionamento social normatizado de acordo com o que se espera de um nobre fidalgo do século XVII ou de um engenheiro de uma megalópole de XXI.

As respostas para estes questionamentos e a tentativa de vivenciar, na concretude da experiência, o ideário da Reforma Psiquiátrica, continua sendo um importante desafio dos movimentos de luta antimanicomial. Dom Quixote, neste sentido, é um ente questionador cujas perguntas não foram ainda, nem de longe, totalmente decifradas.

\section{REFERÊNCIAS}

ALVARENGA, Raphael F. Bovarismo (EL).In: PIZZI, Jovino, CENSI, Maximiliano Sérgio [org.]. Glossario de PatologíasSociales. Pelotas : Ed. UFPel, 2021. Disponível em:http://guaiaca.ufpel.edu.br/bitstream/prefix/7723/1/Glos\%C3\%A1 rio de patolog\%C3\% ADas sociales ebook.pdf. Acesso em: 21 de jul. de 2021.

BARRETTO, Kleber Duarte. Ética e técnica no Acompanhamento Terapêutico: Andanças com Dom Quixote e Sancho Pança. Rio de Janeiro: Unimarco, 1998. 
CERVANTES, Miguel de. Dom Quixote de la Mancha. Trad. Francisco Lopes de Azevedo Velho de Fonseca Barbosa Pinheiro Pereira e Sá Coelho António Feliciano de Castilho. eBooksBrasil, 2005.

MÜLHER-GRANZOTTO, Marcos José; MÜLHER-GRANZOTTO, Rosane Lorena. Psicose e Sofrimento. São Paulo: Summus, 2012.

MULINARI, Maurício. Dom Quixote, um tratado sobre a fantasia e a revolução. Instituto de Estudos Latino-Americanos, UFSC, Florianópolis, 02 de ago. de 2019. Disponível em:https://iela.ufsc.br/noticia/dom-quixote-um-tratado-sobre-fantasia-e-revolucao. Acesso em: 21 de jul. de 2021.

LÜCHMANN, Lígia Helena Hahn; RODRIGUES, Jefferson. O movimento Antimanicomial no Brasil. Ciência Saúde Coletiva, 12(2), 2007. Disponível em:https://doi.org/10.1590/S1413-81232007000200016. Acesso em: 25 de jul. de 2021.

PALOMBINI, Analice de Lima. Acompanhante terapêutico: dispositivo clínico-político. Psyche (Sao Paulo) v.10 n.18 São Paulo set. 2006. Disponível em: http://pepsic. bvsalud.org/scielo.php?script=sci arttext\&pid=S1415-11382006000200012. Acesso em: 23 de jul. de 2021. 